\title{
Degummed crude canola oil, sire breed and gender effects on intramuscular long- chain omega-3 fatty acid properties of raw and cooked lamb meat
}

Aaron Ross Flakemore ${ }^{1}$, Bunmi Sherifat Malau-Aduli ${ }^{2}$, Peter David Nichols ${ }^{3}$ and Aduli Enoch Othniel Malau-Aduli ${ }^{1,4^{*}}$

\begin{abstract}
Background: Omega-3 long-chain ( $\geq C_{20}$ ) polyunsaturated fatty acids ( $\omega 3$ LC-PUFA) confer important attributes to health-conscious meat consumers due to the significant role they play in brain development, prevention of coronary heart disease, obesity and hypertension. In this study, the w3 LC-PUFA content of raw and cooked Longissimus thoracis et lumborum (LTL) muscle from genetically divergent Australian prime lambs supplemented with dietary degummed crude canola oil (DCCO) was evaluated.
\end{abstract}

Methods: Samples of LTL muscle were sourced from 24 first cross ewe and wether lambs sired by Dorset, White Suffolk and Merino rams joined to Merino dams that were assigned to supplemental regimes of degummed crude canola oil (DCCO): a control diet at $0 \mathrm{~mL} / \mathrm{kg}$ DM of DCCO (DCCOC); $25 \mathrm{~mL} / \mathrm{kg}$ DM of DCCO (DCCOM) and $50 \mathrm{~mL} / \mathrm{kg}$ DCCO (DCCOH). Lambs were individually housed and offered $1 \mathrm{~kg} /$ day/head for 42 days before being slaughtered. Samples for cooked analysis were prepared to a core temperature of $70{ }^{\circ} \mathrm{C}$ using conductive dry-heat.

Results: Within raw meats: DCCOH supplemented lambs had significantly $(P<0.05)$ higher concentrations of eicosapentaenoic (EPA, 20:5 w3) and EPA + docosahexaenoic (DHA, 22:6w3) acids than those supplemented with DCCOM or DCCOC; Dorset sired lambs contained significantly $(P<0.05)$ more EPA and EPA + DHA than other sire breeds; diet and sire breed interactions were significant $(P<0.05)$ in affecting EPA and EPA + DHA concentrations. In cooked meat, w3 LC-PUFA concentrations in DCCOM (32 mg/100 g), DCCOH (38 mg/100 g), Dorset (36 mg/100 g), White Suffolk (32 mg/100 g), ewes (32 mg/100 g) and wethers (33 mg/100 g), all exceeded the minimum content of $30 \mathrm{mg} / 100 \mathrm{~g}$ of edible cooked portion of EPA + DHA for Australian defined 'source' level w3 LC-PUFA classification.

Conclusion: These results present that combinations of dietary degummed crude canola oil, sheep genetics and culinary preparation method can be used as effective management tools to deliver nutritionally improved $\omega 3$ LC-PUFA lamb to meat consumers.

Keywords: Canola oil, Lamb, Cooking, Omega-3 fatty acids, Meat quality

\footnotetext{
* Correspondence: aduli.malauaduli@jcu.edu.au

${ }^{1}$ Animal Science and Genetics, Tasmanian Institute of Agriculture, School of Land and Food, Faculty of Science, Engineering and Technology, University of Tasmania, Private Bag 54 Sandy Bay, Hobart, TAS 7001, Australia

${ }^{4}$ Animal Genetics and Nutrition, Veterinary Sciences, College of Public Health, Medical and Veterinary Sciences, Division of Tropical Health and Medicine, James Cook University, Townsville, QLD 4811, Australia

Full list of author information is available at the end of the article
} 


\section{Background}

Ruminant meats are important components of the human diet, particularly in Western countries [1, 2]. However, perceived negative health effects associated with increased saturated fatty acid intakes (i.e. cardiovascular disease, cancers and obesity) are now embedded in the public consciousness [3-5]. Subsequently, consumers are favouring alternative healthier foods, or leaner meats containing less saturated fat and higher concentrations of health promoting omega-3 polyunsaturated fatty acids $[6,7]$. Therefore, an improvement in the content of health beneficial omega-3 long-chain $\left(\geq \mathrm{C}_{20}\right)$ polyunsaturated fatty acids ( $\omega 3$ LC-PUFA); eicosapentaenoic (EPA, 20:5 $\omega 3$ ) and doco-

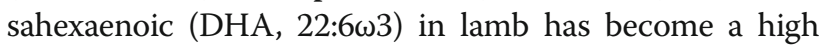
priority for the Australian meat sector [8-10].

Nutritional intervention through dietary lipid supplementation has emerged as an area of interest to manipulate intramuscular fat (IMF) properties of red meats with targeted flow on beneficial effects to human health $[11,12]$. However, endeavours to successfully meet consumer demands for healthier meat products via dietary lipid supplementation have been shown to be complex due to the intricate interactions between dietary factors and rumen metabolism; namely, the level and source of dietary lipids $[13,14]$, the basal diet $[13,14]$ and the potentially limited capacity of $\omega 3$ LC-PUFA to escape rumen biohydrogenation for subsequent metabolic distribution and partitioning into muscle and other tissues [11, 15-17].

In addition to diet, lamb genetics can dictate the nature of the nutritional status of $\omega 3$ LC-PUFA content in meat [18-20], and the response of different sheep breeds to nutritional supplementation. Moreover, genetic predispositions between sheep types based on production traits (i.e. wool $/$ meat $/$ milk) through extensive breeding and crossbreeding directs that fatty acid properties of sheep may respond differently to changes in diet [20, 21]. Therefore, interaction responses between supplementary nutritional input through omega-3 oil sources and sheep types developed for specific production purposes and subsequent effects on meat lipid properties require ongoing investigations are needed.

Increases in commercial canola production throughout Australia have now made canola oil easily available and at a competitively affordable price [22, 23]. To our current knowledge, however, there is a dearth in published data assessing the optimum level of inclusion of degummed canola oil in Australian prime lamb diets for enhancing the health beneficial LC-omega-3 fatty acid concentrations in meats for consumers. In addition, despite a number of studies quantifying the effect of cooking on lamb meat fatty acid properties [24-27], there is very little published information emanating from sheep under on-farm management conditions, assessing the impacts of dietary supplementation, breed, gender and their interactions on FA composition within the raw and cooked meat as prepared for consumption. The objective of this study was to examine the effects of dietary degummed crude canola oil supplementation and its interactions amongst genetically divergent Australian sheep types on selected nutrients (moisture and intramuscular fat content), fatty acid composition and content (with particular emphasis on $\omega-3$ LC-PUFA), and their retention properties in raw and cooked meats. The hypotheses for this study were: (i) DCCO can be successfully included in sheep rations to beneficially manipulate fatty acids in raw meat, which will transpire to the final cooked product, consequently generating a nutritionally beneficial product to the consumer; (ii) genetically divergent lambs demonstrate differences in meat lipid properties that can be amended through dietary DCCO intervention; and (iii) gender plays a minor role in the fatty acid composition of prime lambs supplemented with canola oil.

\section{Methods \\ Animals, management and sample collection}

The experimental conditions for this study have been reported previously [28-30]. To reiterate, the feeding phase of this experiment comprised twenty-four (24) individually housed, 6-month-old, first cross weaner lambs that were assigned to one of three dietary degummed crude canola oil (DCCO) treatments: 1) a control diet (DCCOC) at $0 \mathrm{~mL} / \mathrm{kg} \mathrm{DM}$ of DCCO; 2) an intermediate diet (DCCOM) at a volume $25 \mathrm{~mL} / \mathrm{kg} \mathrm{DM}$ of DCCO; and 3) a high rate $(\mathrm{DCCOH})$ of added $\mathrm{DCCO}$ at $50 \mathrm{~mL} / \mathrm{kg}$ DM. The dietary treatments were based on two wheat/ barley-based rations, one concentrate without DCCO, and the other with canola replacing the barley component in the concentrates at an oil inclusion of 5\%. A full account of the ingredient profiles, proximate compositions and fatty acid profiles is given in Table 1 . Each dietary group comprised of first-cross ewe and wether progeny from Merino dams joined to Dorset, White Suffolk, and Merino sires at a mating ratio of 1:100. Following an initial 21-day adjustment period, each animal was provided $1 \mathrm{~kg}$ of concentrate daily for 42 days. Ad libitum, access to lucerne hay and water was provided throughout the experimental period. At the completion of the feeding trial, all experimental animals, except four (4) purebred Merino ewes, were slaughtered and processed as per Australian commercial operating procedures, thus bringing the number of experimental animals for analyses to 20. Samples of commercially prepared loin chop portions (one each for raw and cooked analysis) comprising the longissimus thoracis et lumborum (LTL) muscle were excised from each carcass, and stored at $-20{ }^{\circ} \mathrm{C}$ until required for analysis. 
Table 1 Ingredients and chemical compositions of experimental diets

\begin{tabular}{|c|c|c|c|}
\hline & $\begin{array}{l}\text { Concentrate } 1 \\
\text { (Added DCCO) }\end{array}$ & $\begin{array}{l}\text { Concentrate } 2 \\
\text { (no added DCCO) }\end{array}$ & $\begin{array}{l}\text { Lucerne } \\
\text { hay }\end{array}$ \\
\hline \multicolumn{4}{|l|}{ Ingredients \% } \\
\hline Barley & - & 25.87 & - \\
\hline Wheat 21\% & 17.00 & 25.00 & - \\
\hline Mill mix & 21.18 & 20.17 & - \\
\hline Paddy rice & 28.00 & 7.26 & - \\
\hline Lupins & - & 16.00 & - \\
\hline Canola meal & 15.44 & - & - \\
\hline Canola oil & 5.00 & - & - \\
\hline GOMF & 8.00 & - & - \\
\hline Limestone 37\% & 1.774 & 2.09 & - \\
\hline Ammonium sulphate & 1.25 & 1.25 & - \\
\hline Salt & 1.00 & 1.00 & - \\
\hline Acid buff & 0.625 & 0.625 & - \\
\hline Sodium bicarb & 0.625 & 0.625 & - \\
\hline Sheep premix & 0.10 & 0.10 & - \\
\hline Bovatec $20 \%$ & 0.01 & 0.01 & - \\
\hline \multicolumn{4}{|l|}{ Proximate composition ${ }^{\mathrm{a}}$} \\
\hline DM & 91.8 & 90.9 & 85.6 \\
\hline$C P$ & 12.7 & 10.4 & 17.0 \\
\hline ADF & 8.0 & 9.0 & 44.9 \\
\hline NDF & 20.0 & 21.1 & 55.2 \\
\hline $\mathrm{EE}$ & 6.2 & 2.1 & 1.5 \\
\hline Ash & 9.7 & 8.9 & 6.8 \\
\hline TDN & 75.7 & 72.0 & 55.4 \\
\hline ME (MJ/kg) & 12.1 & 11.4 & 8.4 \\
\hline \multicolumn{4}{|l|}{ Fatty acid $(\% \text { TFA })^{b}$} \\
\hline $16: 0$ & 26.1 & 32.1 & - \\
\hline 18:0 & 3.8 & 3.8 & - \\
\hline $18: 1 \omega 9$ & 41.9 & 16.5 & - \\
\hline $18: 2 \omega 6$ & 6.9 & 17.7 & - \\
\hline $18: 3 \omega 3$ & 0.5 & 1.6 & - \\
\hline$\Sigma$ SFA & 38.6 & 41.2 & - \\
\hline ¿MUFA & 48.7 & 23.3 & - \\
\hline$\sum$ PUFA & 35.0 & 12.6 & - \\
\hline$\sum \omega 6$ & 20.1 & 10.2 & - \\
\hline$\Sigma \omega 3$ & 14.9 & 0.9 & - \\
\hline
\end{tabular}

\%DM (percentage dry matter), CP (crude protein), ADF (acid detergent fibre), NDF (neutral detergent fiber), EE (ether extractable fat), TDN (total digestible nutrients), ME (metabolisable energy). ${ }^{\mathrm{b}} \Sigma \mathrm{SFA}$ is the sum total of 14:0, 15:0, 16:0, 17:0, 18:0, i15:0, a15:0, i16:0, 16:0FALD, i17:0, i18:0, 18:0FALD, 20:0, 22:0, 23:0, $24: 0$. EMUFA is the sum total of $16: 1 \omega 7 c, 18: 1 \omega 9 c, 18: 1 \omega 7 c, 18: 1 \omega 7 \mathrm{t}$, 14:1, 16:1 $19 \mathrm{c}, 16: 1 \omega 7 \mathrm{t}, 16: 1 \omega 5 \mathrm{c}, 16: 1 \omega 13 \mathrm{t}, 17: 1 \omega 8 \mathrm{c}+\mathrm{a} 17: 0,17: 1,18: 1 \mathrm{a}$, 18:1b, 18:1c, 19:1a, 19:1b, 18:1FALD, 20:1 $111 c, 20: 1 \omega 9 c, 20: 1 \omega 7 c, 20: 1 \omega 5 c$, $22: 1 \omega 11 c, 22: 1 \omega 9 c, 24: 1 \omega 9 c$. $\sum$ PUFA is the sum total of $18: 2 \omega 6,18: 3 \omega 3$, 20:4 $\omega 6,20: 5 \omega 3,22: 6 \omega 3,22: 5 \omega 3,18: 3 \omega 6,18: 4 \omega 3,18: 2 \omega 6 C L A a, 18: 2 \omega 6 C L A b$, $18: 2 \omega 6$ CLAc, 20:3, 20:3 $\omega 6,20: 4 \omega 3,20: 2 \omega 6,22: 5 \omega 6,22: 4 \omega 6 . \Sigma \omega 6=$ is the combined sum total of 18:2 $\omega 6,20: 4 \omega 6,18: 3 \omega 6,20: 3 \omega 6,20: 2 \omega 6,22: 5 \omega 6$, $22: 4 \omega 6 . \Sigma \omega 3=$ is the combined sum total of $18: 3 \omega 3,20: 5 \omega 3,22: 6 \omega 3$, $22: 5 \omega 3,18: 4 \omega 3,20: 4 \omega 3$. Proximate analysis and determination of fatty acid composition of experimental concentrate diets was performed by Otto, et al. [23]

\section{Cooking protocol}

Samples designated for cooking were removed from $-20{ }^{\circ} \mathrm{C}$ storage and placed in a domestic refrigerator at $4{ }^{\circ} \mathrm{C}$ overnight to defrost. Prior to cooking, each sample was denuded of subcutaneous fat with any visible overlaying fat removed. Samples were cooked using conductive dry-heat on a flat surface hotplate using a Barbeques Galore G Series 4 burner (input: $20 \mathrm{MJ} / \mathrm{h}$ per burner) grilling unit with the cooking temperature set to High. No oil or other additives were used, thus negating their potential influence on final nutritional parameters. Samples were cooked until attainment of an internal temperature of $70{ }^{\circ} \mathrm{C}$ degrees, measured using a digital hand-held insta-read food thermometer with the thermocouple inserted into the approximated geometric centre of the LTL muscle. After cooking, each meat sample was rested for approximately three minutes, then sliced from the bone and cut into relatively equally sized portions of $\sim 1 \mathrm{~cm}^{3}$. Cooked sub-sample portions (10-15 g) were stored at $-20{ }^{\circ} \mathrm{C}$ until required for laboratory analysis.

\section{Analysis of moisture, intramuscular fat and fatty acids}

Analysis of the moisture content of LTL muscle from each raw and cooked loin chop was determined as per ISO Reference Method 4442 [31], being dried until constant mass was achieved by means of an air convection oven set to a temperature of $105{ }^{\circ} \mathrm{C}$. Moisture content was expressed as a percentage of the difference of meat mass pre- and post-drying.

Intramuscular fat (IMF) extraction and analysis of fatty acids was performed following the stepwise laboratory lipid analysis protocol described previously in the literature [32]. IMF from each raw and cooked LTL muscle was extracted overnight from a $1 \mathrm{~g}$ sub-sample of non-homogenised muscle using a modified Bligh and Dyer protocol [33], extracted using $\mathrm{CHl}_{3}: \mathrm{MeOH}: \mathrm{H}_{2} \mathrm{O}(1: 2: 0.8 \mathrm{v} / \mathrm{v})$, with phase separation using $\mathrm{CHCl}_{3}$ :Saline Milli-Q $\mathrm{H}_{2} \mathrm{O}(1: 1 v / v)$, and rotary evaporation. This protocol was used to determine IMF content expressed as percentages of the extracted IMF from the LTL muscle. Fatty acid methyl esters (FAME) of the extracted IMF were prepared from a transmethylated aliquot volume of the total IMF, extracted three times using hexane/dichloromethane at a ratio of 4:1. Analysis was performed via capillary gas chromatography (GC) on an Agilent Technologies 7890B GC equipped with a 7683B series auto sampler and flame ionization detector, fitted with a non-polar Equity ${ }^{\mathrm{mm}}-1$ fused silica capillary column (15 m $\times 0.1$ mmi.d., $0.1 \mu$ mfilm thickness), an FID, and split/splitless injector was used. Helium acted as the carrier gas. Peaks were quantified by ChemStation software (Agilent Technologies). Additional analysis was performed to confirm identifications of fatty acid peaks by GC-mass spectrometric (GC-MS) using a Finnigan Thermoquest GCQ GC-MS fitted with an on-column injector and using 
Thermoquest Xcalibur software (Austin, TX, USA). Fatty acids derived from the extracted lipid from each sample were methylated and analysed in duplicate and the data was averaged prior to statistical analysis. Quantitative analysis (mg/100 g) of fatty acid content was calculated from \%FA data obtained from fatty acid area output, using a lipid conversion factor (LCF) of 0.916 [34] as referenced by Greenfield and Southgate [35] using the equation as presented by Clayton [36]: $\mathrm{mg} / 100 \mathrm{~g}=$ (Total lipid)*(LCF $[0.916]) *([\% \mathrm{FA}] / 100) * 1000$. Atherogenic (IA) and thrombogenic (IT) indices were calculated as per Ulbricht and Southgate [37]: IA $=\left[\left(4^{*} 14: 0\right)+16: 0\right] /$ $[($ PPUFA $)+($ LMUFA $)] ;$ IT $=[14: 0+16: 0+18: 0] /$ $\left[\left(0.5^{*} \sum\right.\right.$ MUFA $\left.)+\left(0.5^{*} \sum \omega 6\right)+\left(3^{*} \sum \omega 3\right)+(\omega 3 / \omega 6)\right]$. The Indices of hypocholesterolemic to hypercholesterolemic fatty acids $(\mathrm{h} / \mathrm{H})$ was calculated according to Bessa, et al. [38]: $\mathrm{h} / \mathrm{H}=(18: 1 \omega 9 \mathrm{c}+18: 2 \omega 6+20: 4 \omega 6+18: 3 \omega 3+20: 5 \omega 3+$ $22: 5 \omega 3+22: 6 \omega 3) /(14: 0+16: 0)$. Percentage of apparent nutrient retention values (ARV\%) were calculated as per Murphy, et al. [39]: ARV\% = [nutrient content per g of cooked food (dry basis)]/[nutrient content per g of raw food (dry basis)] " 100.

\section{Statistical analysis}

Statistical testing was performed using Statistical Analysis System (SAS) software version 9.2 (SAS Institute, Cary, NJ, USA) [40]. Summary statistics were first computed and included means and standard errors, appraisal for data entry errors and obvious outliers. ANOVA mixed linear model procedures were employed to test for fixed effects and two-way interactions. Diet, breed of sire and gender were fitted as main effects in the analytical model, with meat preparation as a covariate and fatty acids and retention values as dependent variables. Where significant $(P<0.05)$, pairwise comparisons using Tukey tests were implemented to establish differences between means.

\section{Results}

The primary focus of this study was to determine the effects of dietary degummed crude canola oil supplementation and its interactions with sire breed and gender on selected nutrients (moisture and intramuscular fat content), fatty acid composition and content, and retention values in raw and cooked meats. Therefore, examination of the direct effect of cooking treatment on these parameters was not gauged.

\section{Proximate compositions and fatty acid profiles of experimental feeds}

Proximate compositions and fatty acid profiles of the two primary concentrate rations (with and without the addition of degummed crude canola oil) used during the experimental period are given in Table 1 . The concentrate rations were formulated to a metabolisable energy (ME) value of 11.4-12.1 MJ/kg DM, 10.4-12.7\% DM Crude protein $(\mathrm{CP})$ and $2.1-6.2 \% \mathrm{DM}$ ether extractable (EE) fat between the concentrates with and without degummed canola oil, respectively. The concentrate without added DCCO contained greater proportions of 18:2 $\omega 6$ (6.9-17.7\% of total fatty acids, TFA), 18:3 $\omega 3$ (0.5-1.6\%), $\Sigma$ PUFA (12.6$35.0 \%), \sum \omega 3(0.9-14.9 \%)$, and $\sum \omega 6(10.2-20.1 \%)$, whereas the DCCO added concentrate contained a greater proportion of $\Sigma$ MUFA than the non-added oil concentrate, accounting for $48.7 \%$ and $23.3 \%$ of the TFA, respectively. Oleic acid $(18: 1 \omega 9 \mathrm{c})$ was the main MUFA constituting $41.9 \%$ of the TFA for the DCCO added concentrate.

\section{Degummed crude canola oil supplementation}

Feeding regime effects on moisture, intramuscular fat content, and fatty acid properties are presented in Table 2 . The results show there was no difference $(P>0.05)$ between feeding regimes for moisture or intramuscular fat content percentage, averaging $71.1-60.2 \%$ and $3.4-5.1 \%$ between diets for these nutrients within raw and cooked meats, respectively. In the raw state, lambs fed the DCCOH diet had significantly increased $(P<0.05)$ concentrations of EPA (21.0 mg/100 g muscle) compared to the DCCOC $(17.9 \mathrm{mg} / 100 \mathrm{~g})$ and DCCOM $(16.1 \mathrm{mg} /$ $100 \mathrm{~g})$ diets. The sum total of EPA + DHA was likewise highest for the DCCOH $(28.2 \mathrm{mg} / 100 \mathrm{~g})$, but only significantly $(P<0.05)$ compared to the DCCOM diet $(20.0 \mathrm{mg} /$ $100 \mathrm{~g})$. In the cooked state, $\omega 3$ LC-PUFA concentrations increased linearly with the level of dietary oil inclusion; however, unlike observed for the raw state, there was no statistical difference $(P>0.05)$ between feeding regimes. Excluding the sum total of EPA + DHA in raw meats, the results did not reflect any dietary treatment effect $(P>0.05)$ on the sum total of fatty acid groupings within raw or cooked states. Likewise, there was no dietary effect $(P>0.05)$ on $\mathrm{P} / \mathrm{S}$ or $\omega 6 / \omega 3$ ratios, or for calculations of thrombogenicity (IT) and the ratio of hypocholesterolemic/hypercholesterolemic $(\mathrm{h} / \mathrm{H})$. Within raw meats, there was no difference $(P>0.05)$ for calculated index of atherogenicity (IA) between dietary regimes; however, in the cooked product indices of IA significantly declined $(P<0.05)$ with the addition of DCCO to the diet compared to the control diet.

\section{Sire breed}

Sire breed fixed effects are presented in Table 3. Results show that breed of sire had no effect $(P>0.05)$ on either moisture or IMF content within raw or cooked meats. In the raw state, EPA and the sum total of EPA + DHA were significantly $(P<0.05)$ influenced by sire breed genetics, with lambs from Dorset sired progeny displaying a greater propensity for $\omega 3$ LC-PUFA deposition 
Table 2 Effect of degummed crude canola oil feeding regime on raw and cooked lamb meat quality (LSM \pm SEM)

\begin{tabular}{|c|c|c|c|c|c|c|}
\hline \multirow[b]{2}{*}{ Fatty acids ${ }^{A}$} & \multicolumn{3}{|l|}{ Raw meats } & \multicolumn{3}{|l|}{ Cooked meats } \\
\hline & $\overline{\mathrm{DCCOC}}$ & DCCOM & $\mathrm{DCCOH}$ & $\overline{\mathrm{DCCOC}}$ & DCCOM & $\mathrm{DCCOH}$ \\
\hline MC (\%) & $70.7 \pm 0.6$ & $72.0 \pm 0.6$ & $72.3 \pm 0.5$ & $61.6 \pm 1.0$ & $59.7 \pm 1.6$ & $59.4 \pm 1.7$ \\
\hline IMF (\%) & $3.5 \pm 0.4$ & $3.7 \pm 0.6$ & $2.9 \pm 0.3$ & $5.5 \pm 0.6$ & $5.0 \pm 0.6$ & $4.7 \pm 0.6$ \\
\hline$\sum F A$ & $3203 \pm 379.3$ & $3421 \pm 520.3$ & $2628 \pm 273.6$ & $5030 \pm 591.9$ & $4565 \pm 527.7$ & $4264 \pm 554.7$ \\
\hline 14:0 & $55.4 \pm 10.7$ & $55.7 \pm 12.4$ & $37.2 \pm 5.0$ & $113.5 \pm 21.9$ & $59.6 \pm 11.1$ & $59.7 \pm 7.8$ \\
\hline 16:0 & $722.6 \pm 88.5$ & $769.4 \pm 129.2$ & $549.1 \pm 57.8$ & $1139.0 \pm 129.0$ & $956.1 \pm 116.2$ & $890.7 \pm 119.6$ \\
\hline 18.0 & $537.2 \pm 81.1$ & $606.6 \pm 98.5$ & $434.7 \pm 53.9$ & $834.5 \pm 109.5$ & $833.6 \pm 11.9$ & $726.7 \pm 102.2$ \\
\hline $16: 1 \omega 7 c$ & $41.0 \pm 5.4$ & $39.6 \pm 7.5$ & $26.9 \pm 2.9$ & $71.6 \pm 12.4$ & $49.2 \pm 6.8$ & $45.5 \pm 7.0$ \\
\hline $18: 1 \omega 9 c$ & $1188 \pm 179.2$ & $1258 \pm 205.3$ & $928.5 \pm 106.9$ & $1880 \pm 240.8$ & $1693 \pm 221.7$ & $1561 \pm 210.6$ \\
\hline $18: 1 \omega 7 c$ & $58.9 \pm 5.4$ & $64.3 \pm 8.5$ & $59.4 \pm 4.9$ & $83.5 \pm 8.8$ & $86.5 \pm 9.6$ & $87.9 \pm 13.3$ \\
\hline $18: 1 \omega 7 \mathrm{t}$ & $50.1 \pm 8.8$ & $57.9 \pm 12.8$ & $58.5 \pm 7.5$ & $103.8 \pm 26.0$ & $88.1 \pm 14.5$ & $108.6 \pm 16.9$ \\
\hline 18:2w6 (LA) & $148.1 \pm 11.2$ & $182.2 \pm 22.1$ & $165.4 \pm 16.8$ & $221.6 \pm 17.9$ & $256.2 \pm 28.0$ & $231.6 \pm 28.3$ \\
\hline 18:3w3 (ALA) & $27.6 \pm 4.2$ & $32.8 \pm 4.7$ & $33.1 \pm 4.1$ & $49.0 \pm 9.0$ & $47.7 \pm 5.5$ & $48.7 \pm 7.6$ \\
\hline 20:4w6 (ARA) & $43.8 \pm 4.1$ & $43.0 \pm 4.9$ & $46.8 \pm 2.4$ & $59.2 \pm 8.8$ & $66.5 \pm 7.9$ & $62.7 \pm 7.7$ \\
\hline 20:5w3 (EPA) & $17.9 \pm 1.6^{b}$ & $16.1 \pm 1.4^{b}$ & $21.0 \pm 2.0^{\mathrm{a}}$ & $21.4 \pm 2.2$ & $24.2 \pm 1.8$ & $28.1 \pm 4.0$ \\
\hline 22:6w3 (DHA) & $6.1 \pm 1.3$ & $3.9 \pm 0.5$ & $7.2 \pm 0.7$ & $7.2 \pm 0.8$ & $7.6 \pm 0.8$ & $10.0 \pm 1.9$ \\
\hline 22:5w3 (DPA) & $14.2 \pm 1.5$ & $14.2 \pm 1.2$ & $16.3 \pm 0.8$ & $20.7 \pm 2.2$ & $23.5 \pm 2.0$ & $23.2 \pm 2.9$ \\
\hline$\Sigma S F A$ & $1453 \pm 170.6$ & $1562 \pm 254.9$ & $1137 \pm 130.2$ & $2292 \pm 265.8$ & $2031 \pm 252.2$ & $1853 \pm 242.9$ \\
\hline ¿MUFA & $1448 \pm 202.1$ & $1527 \pm 246.9$ & $1164 \pm 128.4$ & $2307 \pm 309.8$ & $2055 \pm 267.1$ & $1951 \pm 259.1$ \\
\hline$\sum$ PUFA & $301.8 \pm 19.2$ & $331.2 \pm 34.5$ & $326.9 \pm 25.5$ & $430.5 \pm 33.3$ & $479.3 \pm 43.7$ & $460.8 \pm 54.9$ \\
\hline$\Sigma C L A$ & $12.8 \pm 2.1$ & $12.5 \pm 1.9$ & $9.7 \pm 1.0$ & $17.6 \pm 1.4$ & $15.9 \pm 2.1$ & $18.1 \pm 3.0$ \\
\hline$\sum \omega 6$ & $208.2 \pm 14.1$ & $238.9 \pm 27.1$ & $226.0 \pm 19.6$ & $298.6 \pm 26.5$ & $343.0 \pm 36.5$ & $314.4 \pm 36.9$ \\
\hline$\Sigma \omega 3$ & $70.0 \pm 6.0$ & $69.7 \pm 6.4$ & $80.3 \pm 7.1$ & $101.9 \pm 8.7$ & $106.3 \pm 6.2$ & $113.9 \pm 15.4$ \\
\hline$E P A+D H A$ & $24.0 \pm 2.9^{\mathrm{ab}}$ & $20.0 \pm 1.6^{b}$ & $28.2 \pm 2.7^{\mathrm{a}}$ & $28.6 \pm 2.7$ & $31.7 \pm 2.4$ & $38.1 \pm 5.9$ \\
\hline $\mathrm{P} / \mathrm{S}$ & $0.2 \pm 0.0$ & $0.2 \pm 0.0$ & $0.3 \pm 0.0$ & $0.2 \pm 0.0$ & $0.3 \pm 0.0$ & $0.3 \pm 0.0$ \\
\hline $6 / 3$ & $3.1 \pm 0.2$ & $3.5 \pm 0.3$ & $2.9 \pm 0.2$ & $3.0 \pm 0.3$ & $3.2 \pm 0.2$ & $2.8 \pm 0.2$ \\
\hline IA & $0.5 \pm 0.0$ & $0.5 \pm 0.0$ & $0.5 \pm 0.0$ & $0.6 \pm 0.0$ & $0.5 \pm 0.0$ & $0.5 \pm 0.0$ \\
\hline IT & $1.2 \pm 0.1$ & $1.3 \pm 0.1$ & $1.1 \pm 0.0$ & $1.3 \pm 0.0$ & $1.2 \pm 0.0$ & $1.1 \pm 0.0$ \\
\hline$h / H$ & $1.9 \pm 0.1$ & $2.0 \pm 0.1$ & $2.1 \pm 0.0$ & $1.8 \pm 0.1$ & $2.1 \pm 0.1$ & $2.1 \pm 0.1$ \\
\hline
\end{tabular}

${ }^{\mathrm{A}} \mathrm{MC}(\%)=$ Moisture content percentage. IMF $(\%)=$ Intramuscular fat content percentage. $\sum F A$ is the sum total of SFA, MUFA, PUFA; $\Sigma$ SFA is the sum of $14: 0,15: 0$, $16: 0,17: 0,18: 0$, i15:0, a15:0, i16:0, 16:0FALD, i17:0, i18:0, 18:0FALD, 20:0, 22:0, 23:0, 24:0; $\sum$ MUFA is the sum of 16:1 $\omega 7 \mathrm{c}, 18: 1 \omega 9 \mathrm{c}, 18: 1 \omega 7 \mathrm{c}, 18: 1 \omega 7 \mathrm{t}, 14: 1,16: 1 \omega 9 \mathrm{c}$, $16: 1 \omega 7 \mathrm{t}, 16: 1 \omega 5 \mathrm{c}, 16: 1 \omega 13 \mathrm{t}, 17: 1 \omega 8 \mathrm{c}+\mathrm{a17}: 0,17: 1,18: 1 \mathrm{a}, 18: 1 \mathrm{~b}, 18: 1 \mathrm{c}, 19: 1 \mathrm{a}, 19: 1 \mathrm{~b}, 18: 1 \mathrm{FALD}, 20: 1 \omega 11 \mathrm{c}, 20: 1 \omega 9 \mathrm{c}, 20: 1 \omega 7 \mathrm{c}, 20: 1 \omega 5 \mathrm{c}, 22: 1 \omega 11 \mathrm{c}, 22: 1 \omega 9 \mathrm{c}, 24: 1 \omega 9 \mathrm{c}$;

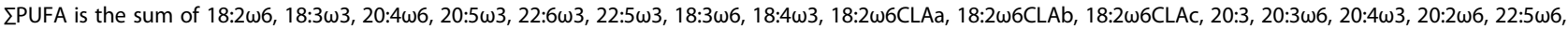

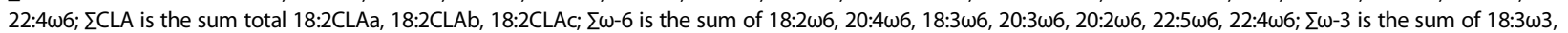
$20: 5 \omega 3,22: 6 \omega 3,22: 5 \omega 3,18: 4 \omega 3,20: 4 \omega 3 ; \sum E P A+D H A$ is the sum of $22: 6 \omega 3$ and $20: 5 \omega 3 ; \mathrm{P} / \mathrm{S}$ is $\Sigma \mathrm{PUFA} / \Sigma \mathrm{SFA} ; 6 / 3$ is $\Sigma \omega 6 / \Sigma \omega 3$; IA $=$ Atherogenic index; IT $=$ Thrombogenic index; $\mathrm{h} / \mathrm{H}=$ hypocholesterolemic to hypercholesterolemic index. DCCOC $=0 \mathrm{~mL} / \mathrm{kg} \mathrm{DM} \mathrm{DCCO}$. DCCOM $=25 \mathrm{~mL} / \mathrm{kg} \mathrm{DM} \mathrm{DCCO}$. DCCOH $=50 \mathrm{~mL} / \mathrm{kg}$ DCCO. Fatty acids are presented on an $\mathrm{mg} / 100 \mathrm{~g}$ muscle tissue basis. Values are least square means and standard error of the means for 6 DCCOC, $7 \mathrm{DCCOM}$, and $7 \mathrm{DDCOH}$ supplemented lambs within raw and cooked analysis. Row means within raw and cooked meats showing differing superscript letters significantly differ $(P<0.05)$

than the other breeds of sire studied. Corresponding to the raw state, $\omega 3$ LC-PUFA concentration in cooked meat was greater under the influence of Dorset sire genetics; however, the observed significant differences between sires for $\omega 3$ LC-PUFA content in raw meats were not statistically evident $(P>0.05)$. All summations, ratios and indices, except the sum total of $\mathrm{EPA}+\mathrm{DHA}$ in raw meat, were shown to be not influenced $(P>0.05)$ by breed of sire effect for meats in both the raw and cooked states.

\section{Gender}

The results, as presented in Table 4, report no difference $(P>0.05)$ between ewe and wether lambs for moisture content, IMF content, concentrations of individual fatty acids, their partial sums, ratios and indices within either raw or cooked meats.

\section{Interactions}

In the raw meat, significant $(P<0.05)$ sire breed by diet in-

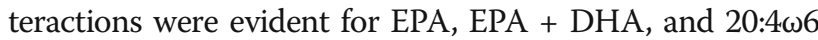


Table 3 Breed of sire influence on raw and cooked lamb meat quality (LSM \pm SEM)

\begin{tabular}{|c|c|c|c|c|c|c|}
\hline \multirow[b]{2}{*}{ Fatty acids ${ }^{\mathrm{A}}$} & \multicolumn{3}{|l|}{ Raw meats } & \multicolumn{3}{|c|}{ Cooked meats } \\
\hline & Dorset & White Suffolk & Merino & Dorset & White Suffolk & Merino \\
\hline MC (\%) & $71.4 \pm 0.5$ & $72.4 \pm 0.4$ & $70.9 \pm 1.1$ & $60.8 \pm 1.2$ & $60.3 \pm 1.4$ & $59.0 \pm 2.0$ \\
\hline IMF (\%) & $3.5 \pm 0.3$ & $3.1 \pm 0.5$ & $3.9 \pm 0.7$ & $5.9 \pm 0.7$ & $4.3 \pm 0.4$ & $5.0 \pm 0.6$ \\
\hline$\sum F A$ & $3198 \pm 234$ & $2797 \pm 437$ & $3542 \pm 676$ & $5375 \pm 615$ & $3976 \pm 350$ & $4573 \pm 514$ \\
\hline 14:0 & $53.6 \pm 8.7$ & $42.1 \pm 10.0$ & $58.4 \pm 14.1$ & $98.7 \pm 22.1$ & $57.4 \pm 8.6$ & $76.7 \pm 13.7$ \\
\hline $16: 0$ & $701.4 \pm 51.2$ & $606.4 \pm 101.8$ & $813.6 \pm 181.9$ & $1149 \pm 139$ & $865 . \pm 82.4$ & $975.9 \pm 132$ \\
\hline 18.0 & $570.7 \pm 57.6$ & $459.3 \pm 78.3$ & $602.2 \pm 139.4$ & $961.8 \pm 109$ & $654.0 \pm 64.1$ & $809.3 \pm 116$ \\
\hline $16: 1 \omega 7 c$ & $35.1 \pm 3.9$ & $32.8 \pm 6.4$ & $44.2 \pm 9.0$ & $65.1 \pm 12.6$ & $47.8 \pm 6.0$ & $52.2 \pm 7.1$ \\
\hline $18: 1 \omega 9 c$ & $1143 \pm 98.4$ & $1009 \pm 174$ & $1357 \pm 293$ & $1978 \pm 260$ & $1491 \pm 143$ & $1681 \pm 219$ \\
\hline $18: 1 \omega 7 c$ & $58.4 \pm 4.6$ & $62.6 \pm 7.2$ & $62.6 \pm 8.6$ & $90.6 \pm 10.9$ & $85.4 \pm 9.9$ & $79.0 \pm 7.4$ \\
\hline $18: 1 \omega 7 \mathrm{t}$ & $59.3 \pm 7.7$ & $54.2 \pm 11.1$ & $52.0 \pm 11.7$ & $121.1 \pm 22.0$ & $83.5 \pm 12.4$ & $93.6 \pm 20.2$ \\
\hline 18:2w6 (LA) & $166.1 \pm 8.1$ & $162.0 \pm 22.0$ & $174.4 \pm 23.2$ & $260.6 \pm 19.1$ & $213.7 \pm 27.7$ & $244.7 \pm 18.3$ \\
\hline 18:3w3 (ALA) & $36.2 \pm 3.2$ & $27.6 \pm 4.1$ & $29.7 \pm 6.0$ & $61.4 \pm 7.5$ & $39.3 \pm 3.5$ & $44.1 \pm 6.2$ \\
\hline 20:4w6 (ARA) & $45.5 \pm 3.5$ & $44.5 \pm 3.8$ & $42.5 \pm 5.5$ & $64.5 \pm 7.2$ & $62.2 \pm 9.1$ & $62.0 \pm 3.2$ \\
\hline 20:5w3 (EPA) & $21.0 \pm 1.7^{\mathrm{a}}$ & $16.6 \pm 1.4^{b}$ & $16.6 \pm 2.0^{b}$ & $26.6 \pm 3.1$ & $23.7 \pm 2.6$ & $22.7 \pm 2.5$ \\
\hline 22:6w3 (DHA) & $6.7 \pm 0.8$ & $5.6 \pm 0.9$ & $3.8 \pm 1.4$ & $9.4 \pm 1.4$ & $8.1 \pm 1.1$ & $6.3 \pm 0.8$ \\
\hline 22:5w3 (DPA) & $15.5 \pm 1.0$ & $15.6 \pm 1.0$ & $12.3 \pm 1.6$ & $23.5 \pm 1.9$ & $22.7 \pm 2.7$ & $20.6 \pm 1.5$ \\
\hline$\sum$ SFA & $1464 \pm 110.0$ & $1228 \pm 206.0$ & $1600 \pm 344.3$ & $2432 \pm 275$ & $1727 \pm 156$ & $2062 \pm 250$ \\
\hline$\sum$ MUFA & $1405 \pm 118$ & $1254 \pm 209$ & $1624 \pm 336$ & $2438 \pm 326$ & $1828 \pm 176$ & $2060 \pm 243$ \\
\hline ¿PUFA & $329.8 \pm 16.7$ & $314.0 \pm 31.3$ & $317.5 \pm 36.8$ & $504.4 \pm 31.3$ & $420.7 \pm 49.0$ & $451.4 \pm 28.1$ \\
\hline$\Sigma C L A$ & $10.8 \pm 1.1$ & $12.5 \pm 2.0$ & $11.8 \pm 2.1$ & $19.6 \pm 2.2$ & $14.1 \pm 1.4$ & $18.7 \pm 2.9$ \\
\hline$\Sigma \omega 6$ & $225.7 \pm 11.4$ & $221.8 \pm 25.8$ & $230.8 \pm 26.7$ & $344.6 \pm 24.4$ & $295.8 \pm 39.1$ & $325.1 \pm 20.2$ \\
\hline$\sum \omega 3$ & $82.2 \pm 5.8$ & $68.8 \pm 5.3$ & $66.2 \pm 8.2$ & $124.9 \pm 7.9$ & $97.4 \pm 9.2$ & $96.1 \pm 7.2$ \\
\hline $\mathrm{EPA}+\mathrm{DHA}$ & $27.7 \pm 2.4^{\mathrm{a}}$ & $22.2 \pm 2.1^{b}$ & $20.4 \pm 3.3^{b}$ & $36.0 \pm 4.5$ & $31.8 \pm 3.6$ & $29.1 \pm 2.7$ \\
\hline $\mathrm{P} / \mathrm{S}$ & $0.2 \pm 0.0$ & $0.3 \pm 0.0$ & $0.2 \pm 0.1$ & $0.2 \pm 0.0$ & $0.3 \pm 0.0$ & $0.2 \pm 0.0$ \\
\hline$\omega 6 / \omega 3$ & $2.8 \pm 0.1$ & $3.3 \pm 0.3$ & $3.6 \pm 0.1$ & $2.8 \pm 0.2$ & $3.0 \pm 0.2$ & $3.4 \pm 0.1$ \\
\hline IA & $0.5 \pm 0.0$ & $0.5 \pm 0.0$ & $0.5 \pm 0.0$ & $0.5 \pm 0.0$ & $0.5 \pm 0.0$ & $0.5 \pm 0.0$ \\
\hline IT & $1.2 \pm 0.1$ & $1.1 \pm 0.0$ & $1.3 \pm 0.1$ & $1.2 \pm 0.0$ & $1.2 \pm 0.0$ & $1.2 \pm 0.0$ \\
\hline$h / H$ & $1.9 \pm 0.1$ & $2.0 \pm 0.1$ & $1.9 \pm 0.1$ & $2.0 \pm 0.1$ & $2.1 \pm 0.1$ & $2.0 \pm 0.1$ \\
\hline
\end{tabular}

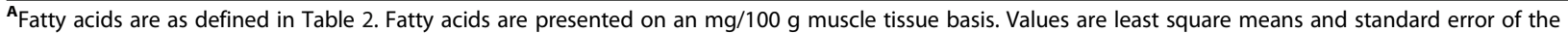
means for 8 Dorset, 8 White Suffolk, and 4 Merino sired lambs within raw and cooked analysis. Row means within raw and cooked meats showing differing superscript letters significantly differ $(P<0.05)$

(ARA) (Fig. 1). In terms of overall effect, both muscle EPA and EPA + DHA concentration showed similar patterns of response whereby the concentration of these fatty acids in the muscle of Dorset and Merino sired lambs tended to increase with the volume of DCCO added in the diet, whereas for White Suffolk sired lambs the concentrations of these fatty acids tended to decline. In terms of ARA concentration, pure Merino demonstrated a greater concentration of this fatty acid within the muscle as a response to the DCCOH level of supplementation compared to the other diets, whereas for Dorset and White Suffolk the greatest response was from the DCCOM level of supplementation which shown to increase and decrease in concentration for these sire breeds, respectively.
Additionally in the raw state, a gender by diet interaction effect $(P<0.05)$ was identified for ARA and $\sum \omega 6$ (Fig. 2). These results were mainly derived from differences between ewes and wethers under the Medium (DCCOM) level of supplementation. In the cooked state, a significant $(P<0.05) \omega 6 / \omega 3$ difference occurred between gender and dietary supplementation (Fig. 2), with the major influence between ewe and wether lambs under the control (DCCOC) diet, and between the control diet and medium level (DCCOM) of supplementation within ewes. All other interactions within raw or cooked meats were shown not to be significant $(P>0.05)$; therefore this data has been omitted from the manuscript. 
Table 4 Gender influence on raw and cooked lamb meat quality (LSM \pm SEM)

\begin{tabular}{|c|c|c|c|c|}
\hline \multirow[b]{2}{*}{ Fatty acids ${ }^{\mathrm{A}}$} & \multicolumn{2}{|l|}{ Raw meat } & \multicolumn{2}{|l|}{ Cooked meat } \\
\hline & Ewe & Wether & Ewe & Wether \\
\hline MC (\%) & $72.6 \pm 0.6$ & $71.2 \pm 0.4$ & $61.4 \pm 1.1$ & $59.5 \pm 1.1$ \\
\hline IMF (\%) & $3.2 \pm 0.5$ & $3.5 \pm 0.3$ & $5.8 \pm 0.6$ & $4.6 \pm 0.4$ \\
\hline$\sum F A$ & $2963 \pm 475.2$ & $3182 \pm 280.1$ & $5292 \pm 548.9$ & $4223 \pm 342.9$ \\
\hline 14:0 & $50.2 \pm 13.7$ & $49.5 \pm 5.6$ & $90.3 \pm 24.4$ & $68.7 \pm 6.9$ \\
\hline 16:0 & $637.9 \pm 112.4$ & $712.6 \pm 70.2$ & $1123 \pm 135.5$ & $917.4 \pm 74.7$ \\
\hline 18.0 & $481.2 \pm 86.4$ & $559.2 \pm 58.2$ & $908.7 \pm 102.4$ & $736.8 \pm 71.5$ \\
\hline $16: 1 \omega 7 c$ & $35.3 \pm 7.1$ & $36.4 \pm 4.0$ & $65.9 \pm 12.6$ & $48.8 \pm 4.4$ \\
\hline $18: 1 \omega 9 c$ & $1055 \pm 186.0$ & $1177 \pm 121.1$ & $1990 \pm 222.1$ & $1547 \pm 137.7$ \\
\hline $18: 1 \omega 7 c$ & $61.5 \pm 7.6$ & $60.8 \pm 4.2$ & $103.7 \pm 9.4$ & $75.7 \pm 5.8$ \\
\hline $18: 1 \omega 7 t$ & $59.2 \pm 12.6$ & $53.5 \pm 5.8$ & $128.3 \pm 20.2$ & $82.7 \pm 9.9$ \\
\hline 18:2w6 (LA) & $174.7 \pm 22.9$ & $161.1 \pm 10.2$ & $265.7 \pm 27.6$ & $221.1 \pm 15.0$ \\
\hline 18:3w3 (ALA) & $31.9 \pm 4.5$ & $30.8 \pm 3.0$ & $57.5 \pm 7.1$ & $43.2 \pm 4.3$ \\
\hline 20:4w6 (ARA) & $48.4 \pm 3.0$ & $42.2 \pm 3.0$ & $66.3 \pm 9.8$ & $61.1 \pm 4.6$ \\
\hline 20:5w3 (EPA) & $19.2 \pm 1.5$ & $17.6 \pm 1.4$ & $24.3 \pm 2.5$ & $24.7 \pm 2.2$ \\
\hline 22:6w3 (DHA) & $6.1 \pm 1.0$ & $5.4 \pm 0.7$ & $7.9 \pm 1.1$ & $8.4 \pm 1.0$ \\
\hline 22:5w3 (DPA) & $16.7 \pm 0.9$ & $13.8 \pm 0.8$ & $23.6 \pm 2.7$ & $21.9 \pm 1.5$ \\
\hline$\sum S F A$ & $1307 \pm 225.5$ & $1444 \pm 137.9$ & $2324 \pm 272.4$ & $1902 \pm 156.7$ \\
\hline$\sum$ MUFA & $1314 \pm 224.8$ & $1430 \pm 139.1$ & $2464 \pm 280.6$ & $1890 \pm 163.6$ \\
\hline$\sum$ PUFA & $341.9 \pm 29.6$ & $308.1 \pm 17.8$ & $503.9 \pm 43.6$ & $431.3 \pm 28.7$ \\
\hline$\sum \mathrm{CLA}$ & $13.4 \pm 2.2$ & $10.7 \pm 0.9$ & $19.3 \pm 1.8$ & $15.8 \pm 1.6$ \\
\hline$\sum \omega 6$ & $239.4 \pm 25.7$ & $216.8 \pm 12.8$ & $352.3 \pm 38.2$ & $301.1 \pm 19.8$ \\
\hline$\Sigma \omega 3$ & $77.5 \pm 5.2$ & $70.7 \pm 5.1$ & $117.5 \pm 6.4$ & $101.3 \pm 8.1$ \\
\hline $\mathrm{EPA}+\mathrm{DHA}$ & $25.3 \pm 2.3$ & $23.0 \pm 2.0$ & $32.2 \pm 3.5$ & $33.1 \pm 3.1$ \\
\hline $\mathrm{P} / \mathrm{S}$ & $0.3 \pm 0.0$ & $0.2 \pm 0.0$ & $0.2 \pm 0.0$ & $0.2 \pm 0.0$ \\
\hline$\omega 6 / \omega 3$ & $3.2 \pm 0.3$ & $3.2 \pm 0.1$ & $3.0 \pm 0.3$ & $3.0 \pm 0.1$ \\
\hline IA & $0.5 \pm 0.0$ & $0.5 \pm 0.0$ & $0.5 \pm 0.0$ & $0.5 \pm 0.0$ \\
\hline IT & $1.1 \pm 0.0$ & $1.2 \pm 0.0$ & $1.2 \pm 0.1$ & $1.2 \pm 0.0$ \\
\hline$h / H$ & $2.0 \pm 0.1$ & $1.9 \pm 0.1$ & $2.1 \pm 0.1$ & $2.0 \pm 0.0$ \\
\hline
\end{tabular}

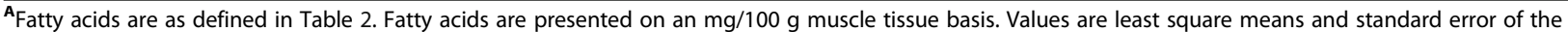
means for 8 ewe and 12 wether lambs within raw and cooked analysis. Row means within raw and cooked meats showing differing superscript letters significantly differ $(P<0.05)$

\section{Retention of nutrients}

Coefficients of apparent nutrient retention are presented in Table 5. Feeding regime or sire breed was shown not to be a factor $(P>0.05)$ in the ability of meats to retain nutrients (ARV \%) as a function of the cooking process. In terms of gender, meat from ewe lambs demonstrated significantly $(P<0.05)$ superior ARV\% than wethers for IMF/sum total of fatty acids, and the sum totals of SFA and MUFA, as well as for the major individual fatty acids comprising the overall fatty acid profile $(18: 1 \omega 9 \mathrm{c}, 16: 0$, 18:0). In effect, the ARV\% of these values exceeded $100 \%$ for ewe lambs, whereas for wethers these were consistently less than $100 \%$.

\section{Discussion}

\section{Degummed crude canola oil supplementation}

In this study, both moisture and intramuscular fat content percentages of the LTL muscle were not dependent on the inclusion of oil in the diet regardless of cooking state. Moisture content observations are consistent with previous studies [38, 41, 42] reporting water-holding properties of small ruminant meats. In terms of IMF, the lack of difference between dietary groups herein is consistent with previous findings for raw longissimus muscle from lambs supplemented with canola seeds and meals [43, 44]. Increases in IMF content in cooked meats without significant effect amongst dietary treatments correspond with 

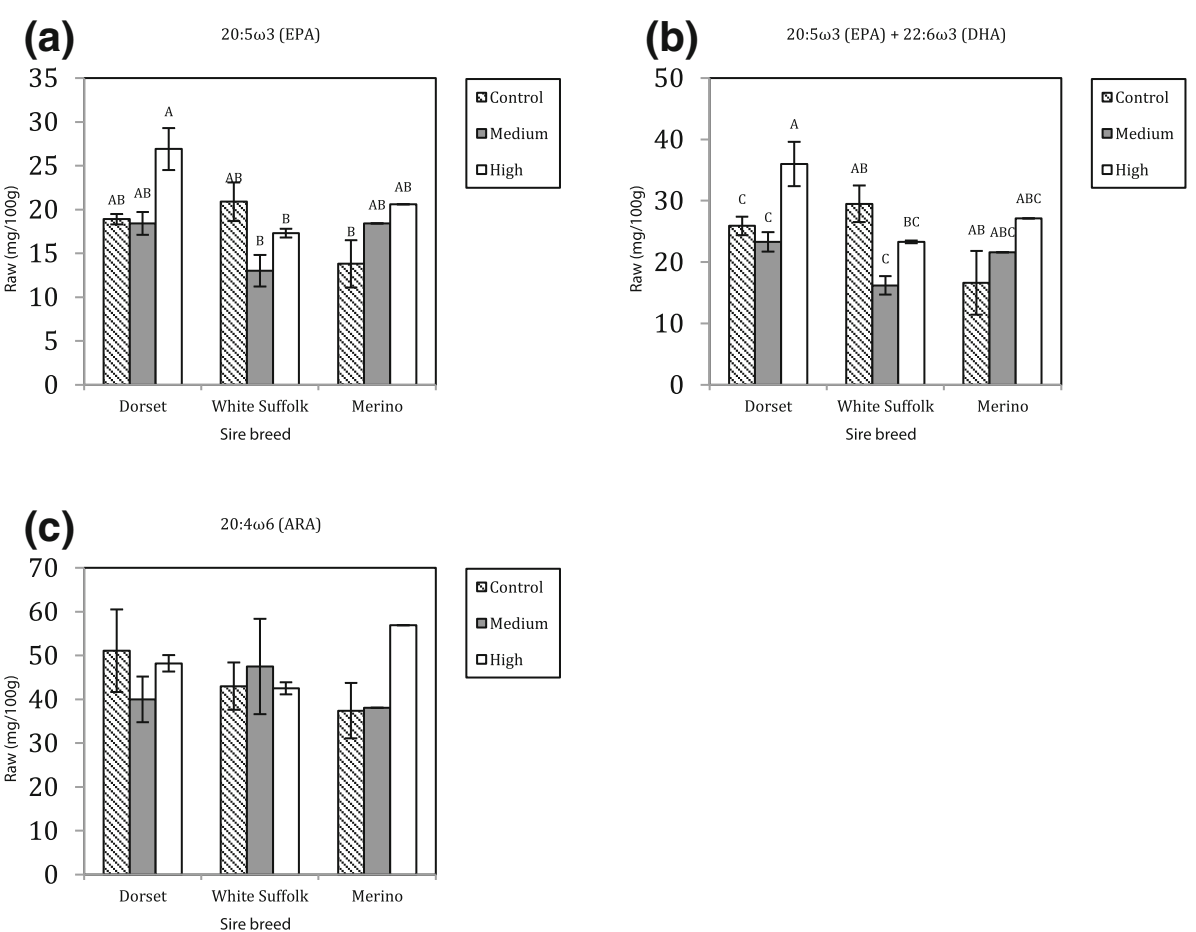

Fig. 1 Feeding regime by sire breeds interactions in raw meat. a EPA; $\mathbf{b} ; E P A+D H A ; \mathbf{c} A R A$

the non-significant reduction in meat moisture content post-cooking, and is a finding consistent with the inverse relationship between these two meat properties.

In the raw state, the concentrations ( $\mathrm{mg} / 100 \mathrm{~g}$ muscle) of $\omega 3$ LC-PUFA (EPA, $21 \mathrm{mg} / 100 \mathrm{~g}$; DHA, $7.2 \mathrm{mg} /$
$100 \mathrm{~g}$; DPA $16 \mathrm{mg} / 100 \mathrm{~g}$ ) for the $\mathrm{DCCOH}$ diet were similar to those reported by Ponnampalam, et al. [44] for the longissimus muscle of Australian 2nd-cross ([Merino $\times$ Border Leicester $] \times$ Poll Dorset) wether lambs supplemented with canola meal (EPA, $15.2 \mathrm{mg} / 100 \mathrm{~g}$;
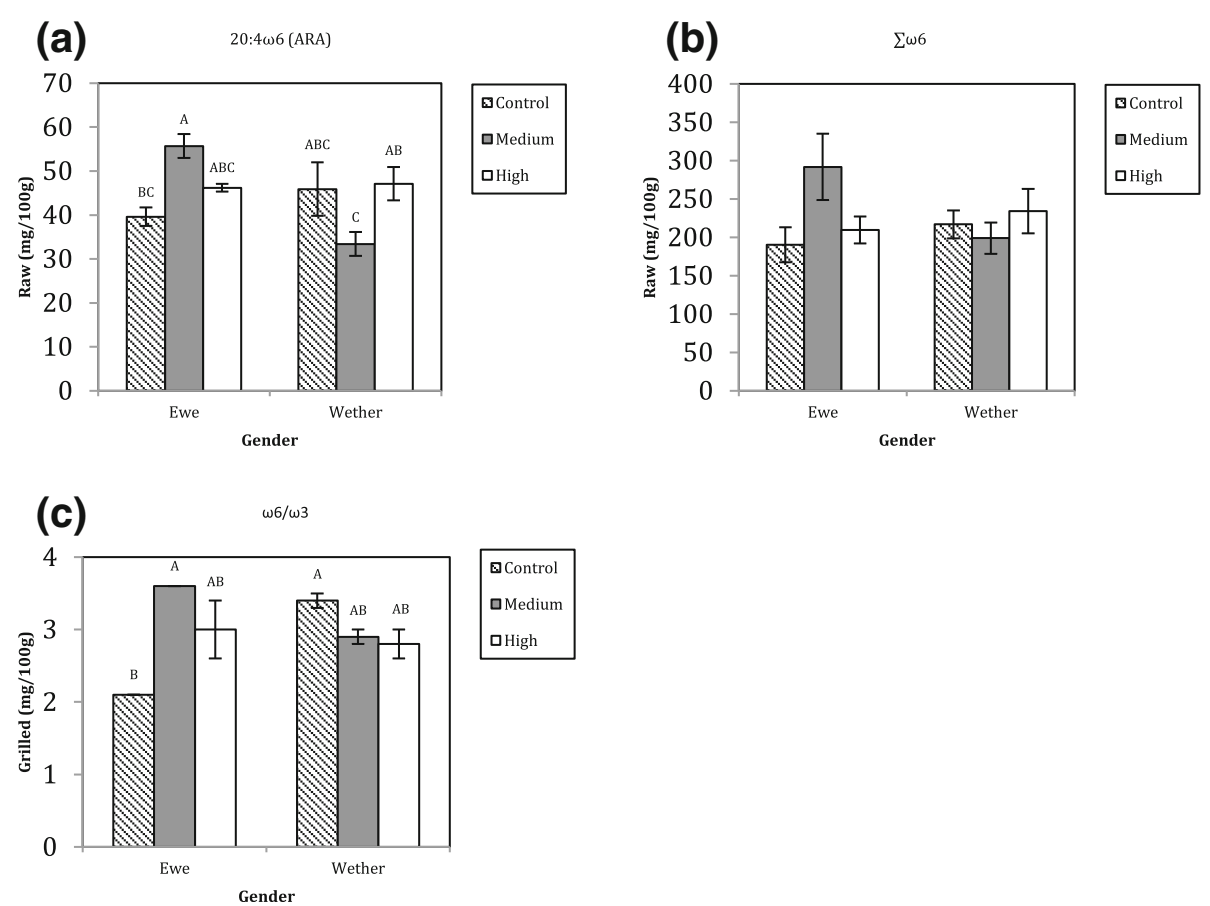

Fig. 2 Feeding regime and gender interactions. a ARA; b $\sum \omega 6$ raw; c $\omega 6 / \omega 3$ cooked meats 
Table 5 Apparent retention values of fatty acids based on feeding regime, sire breed and gender

\begin{tabular}{|c|c|c|c|c|c|c|c|c|}
\hline \multirow[b]{2}{*}{ Fatty acids ${ }^{\mathrm{A}}$} & \multicolumn{3}{|c|}{ Feeding regime } & \multicolumn{3}{|l|}{ Sire breed } & \multicolumn{2}{|l|}{ Gender } \\
\hline & $\overline{D C C O C}$ & DCCOM & $\mathrm{DCCOH}$ & Dorset & White Suffolk & Merino & Ewe & Wether \\
\hline Moisture (\%) & $67.7 \pm 3.3$ & $61.2 \pm 3.0$ & $52.2 \pm 4.5$ & $62.6 \pm 3.6$ & $58.9 \pm 3.9$ & $60.7 \pm 6.9$ & $62.1 \pm 3.9$ & $59.9 \pm 3.2$ \\
\hline IMF (\%) & $126.3 \pm 18.2$ & $107.2 \pm 19.9$ & $103.9 \pm 8.4$ & $127.2 \pm 21.3$ & $107.1 \pm 11.9$ & $96.2 \pm 7.3$ & $141.1 \pm 20.6^{a}$ & $95.3 \pm 5.0^{\mathrm{b}}$ \\
\hline$\sum$ fatty acids & $126.3 \pm 18.2$ & $107.2 \pm 19.9$ & $103.9 \pm 8.4$ & $127.2 \pm 21.3$ & $107.1 \pm 11.9$ & $96.2 \pm 7.3$ & $141.1 \pm 20.6^{a}$ & $95.3 \pm 5.0^{b}$ \\
\hline 14:0 & $163.5 \pm 15.2$ & $105.8 \pm 36.8$ & $105.3 \pm 6.7$ & $144.6 \pm 33.2$ & $112.4 \pm 17.7$ & $110.4 \pm 29.3$ & $155.2 \pm 35.8$ & $105.6 \pm 10.4$ \\
\hline $16: 0$ & $128.0 \pm 18.4$ & $103.0 \pm 22.0$ & $104.0 \pm 7.6$ & $124.8 \pm 21.9$ & $109.5 \pm 13.9$ & $91.0 \pm 8.6$ & $141.2 \pm 22.5^{a}$ & $93.7 \pm 5.1^{b}$ \\
\hline 18.0 & $128.1 \pm 21.6$ & $114.8 \pm 26.3$ & $107.7 \pm 11.9$ & $134.3 \pm 27.8$ & $109.3 \pm 14.6$ & $100.9 \pm 7.1$ & $153.7 \pm 25.7^{\mathrm{a}}$ & $95.2 \pm 6.6^{b}$ \\
\hline $16: 1 \omega 7 c$ & $139.5 \pm 20.8$ & $103.7 \pm 22.0$ & $109.0 \pm 11.3$ & $136.3 \pm 23.1$ & $112.6 \pm 14.2$ & $90.5 \pm 14.3$ & $146.5 \pm 24.4$ & $99.3 \pm 7.2$ \\
\hline $18: 1 \omega 9 c$ & $134.8 \pm 26.0$ & $107.9 \pm 20.7$ & $108.0 \pm 8.1$ & $132.6 \pm 25.1$ & $113.8 \pm 14.7$ & $93.3 \pm 6.6$ & $152.2 \pm 24.4^{\mathrm{a}}$ & $95.6 \pm 5.5^{b}$ \\
\hline $18: 1 \omega 7 c$ & $112.6 \pm 16.2$ & $103.0 \pm 14.7$ & $92.8 \pm 8.6$ & $115.7 \pm 17.9$ & $96.9 \pm 8.9$ & $92.0 \pm 6.7$ & $127.9 \pm 16.4^{a}$ & $88.2 \pm 3.9^{b}$ \\
\hline $18: 1 \omega 7 \mathrm{t}$ & $166.5 \pm 36.1$ & $135.6 \pm 37.3$ & $118.2 \pm 13.7$ & $167.8 \pm 44.6$ & $117.9 \pm 15.6$ & $134.8 \pm 17.6$ & $187.6 \pm 41.1^{\mathrm{a}}$ & $112.0 \pm 10.3^{b}$ \\
\hline $18: 2 \omega 6$ (LA) & $115.6 \pm 8.6$ & $107.2 \pm 12.5$ & $91.6 \pm 11.5$ & $113.8 \pm 8.0$ & $96.6 \pm 11.3$ & $106.3 \pm 17.3$ & $114.8 \pm 11.9$ & $99.2 \pm 7.5$ \\
\hline 18:3w3 (ALA) & $140.1 \pm 19.1$ & $115.6 \pm 18.2$ & $93.9 \pm 9.2$ & $127.9 \pm 20.1$ & $107.9 \pm 14.4$ & $113.6 \pm 18.0$ & $140.7 \pm 20.7$ & $102.4 \pm 8.5$ \\
\hline 20:4w6 (ARA) & $104.8 \pm 15.7$ & $117.6 \pm 15.5$ & $87.4 \pm 11.3$ & $101.2 \pm 7.3$ & $101.0 \pm 15.8$ & $115.0 \pm 24.8$ & $95.0 \pm 9.4$ & $109.3 \pm 12.2$ \\
\hline 20:5w3 (EPA) & $92.9 \pm 7.4$ & $114.4 \pm 15.5$ & $85.9 \pm 9.2$ & $91.3 \pm 7.5$ & $103.8 \pm 14.8$ & $100.8 \pm 12.7$ & $90.2 \pm 7.7$ & $103.5 \pm 10.3$ \\
\hline 22:6w3 (DHA) & $254.8 \pm 169.0$ & $169.0 \pm 44.7$ & $90.7 \pm 14.2$ & $104.3 \pm 13.5$ & $137.5 \pm 43.2$ & $356.4 \pm 247.9$ & $129.6 \pm 49.3$ & $195.7 \pm 82.8$ \\
\hline 22:5w3 (DPA) & $120.0 \pm 21.7$ & $126.5 \pm 16.7$ & $92.3 \pm 11.3$ & $109.8 \pm 8.5$ & $107.0 \pm 17.0$ & $133.6 \pm 32.3$ & $101.1 \pm 12.0$ & $121.0 \pm 14.0$ \\
\hline$\sum$ SFA & $126.2 \pm 16.8$ & $107.5 \pm 22.8$ & $104.8 \pm 8.5$ & $127.4 \pm 22.8$ & $107.3 \pm 12.6$ & $97.3 \pm 8.4$ & $142.2 \pm 22.3^{a}$ & $95.3 \pm 5.3^{b}$ \\
\hline$\sum$ MUFA & $132.6 \pm 24.2$ & $108.1 \pm 20.9$ & $107.2 \pm 8.0$ & $132.6 \pm 25.0$ & $110.8 \pm 13.1$ & $95.3 \pm 7.0$ & $149.9 \pm 23.7^{\mathrm{a}}$ & $95.5 \pm 5.2^{\mathrm{b}}$ \\
\hline$\sum$ PUFA & $110.3 \pm 9.4$ & $109.6 \pm 12.1$ & $91.4 \pm 10.7$ & $110.5 \pm 5.3$ & $96.9 \pm 12.1$ & $107.2 \pm 17.3$ & $108.3 \pm 10.4$ & $101.6 \pm 8.2$ \\
\hline$\Sigma \mathrm{CLA}$ & $119.1 \pm 19.9$ & $108.7 \pm 28.2$ & $119.0 \pm 15.0$ & $143.0 \pm 25.7$ & $88.8 \pm 12.6$ & $119.7 \pm 20.1$ & $125.2 \pm 27.6$ & $109.5 \pm 12.2$ \\
\hline$\Sigma \omega 6$ & $110.4 \pm 9.0$ & $108.7 \pm 12.1$ & $90.8 \pm 11.2$ & $110.0 \pm 5.6$ & $96.5 \pm 11.9$ & $106.5 \pm 17.8$ & $108.2 \pm 10.6$ & $100.9 \pm 8.2$ \\
\hline$\Sigma \omega 3$ & $113.2 \pm 9.9$ & $115.8 \pm 12.8$ & $91.1 \pm 9.4$ & $110.9 \pm 6.2$ & $103.1 \pm 13.2$ & $108.9 \pm 16.2$ & $111.3 \pm 10.3$ & $104.8 \pm 8.8$ \\
\hline $\mathrm{EPA}+\mathrm{DHA}$ & $96.8 \pm 12.0$ & $120.1 \pm 15.7$ & $87.1 \pm 10.4$ & $94.2 \pm 8.8$ & $105.8 \pm 15.8$ & $109.7 \pm 18.0$ & $92.8 \pm 11.0$ & $107.9 \pm 10.9$ \\
\hline
\end{tabular}

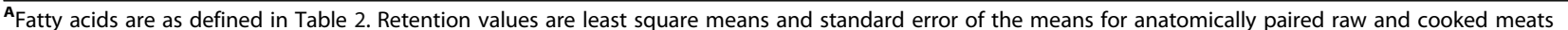
from the same animal based on 6 DCCOC, 7 DCCOM, 7 DCCOH, 8 Dorset, 8 White Suffolk, 4 Merino, 8 ewe and 12 wether lambs. Data means within the same row within fatty acids within production variable effect with different superscript letters significantly differ $(P<0.05)$

DHA, $5 \mathrm{mg} / 100 \mathrm{~g}$; DPA, $17 \mathrm{mg} / 100 \mathrm{~g}$ ) and protected canola seed (EPA, $12.8 \mathrm{mg} / 100 \mathrm{~g}$; DHA, $4.8 \mathrm{mg} / 100 \mathrm{~g}$; DPA, $15 \mathrm{mg} / 100 \mathrm{~g}$ ), albeit with concentrations of EPA and DHA in the current study slightly higher. Unlike the findings herein, however, Ponnampalam, et al. [44] did not detect significant $\omega 3$ LC-PUFA concentration effects with the application of either forms of canola when comparing to a control diet of mixed lucerne and oaten chaff offered at alternative ratios. In this respect, it can be argued that despite these forms of canola providing relatively high amounts of $\alpha$-linolenic acid (ALA, 18:3 $\omega 3$; 1404-3459 mg/ total $\omega 3$ intake/day for canola meal and protected seed, respectively), there was insufficient rumen by-pass from these feed sources to induce increases in the $\omega 3$ LC-PUFA content of muscle tissue. This observation has been reported by Karami, et al. [45], when they compared canola oil with palm oil supplementation for compositional changes in the longissimus muscle tissue of goats. Results herein suggest, however, that the higher volume of lipid associated with the $\mathrm{DCCOH}$ diet did not seem to impair rumen microbial activities, and that this dietary oil source was more efficient than the other diets (particularly compared to the DCCOM diet) in utilising the ALA conversion to and deposition of $\omega 3$ LCPUFA into the muscle. Essentially, this indicates that the physiochemical characteristics of $\mathrm{DCCOH}$ and mode of application influenced the degree to which dietary oil escaped rumen biohydrogenation. Alternatively, the meat from $\mathrm{DCCOH}$ supplemented lambs may have contained a greater proportion of phospholipids as a percentage of the total lipids, a factor that increases the concentration of PUFA in meats $[5,12,17]$.

The observed non-significant $\omega 3$ LC-PUFA results between feeding regimes in the cooked state suggests some meats within dietary treatments may have displayed a greater susceptibility to heat induced oxidative degradation of $\omega 3$ LC-PUFA than others. On assessment of the data, it appears this was likely due to the non-significant differences in ARV \% for these fatty acid types, particularly with reference to the lower rates of retention 
of $\omega 3$ LC-PUFA under DCCOH supplementation compared to the other diets. In previous research, Badiani, et al. [25] and Maranesi, et al. [27] suggested that cooking processes can differ between meats due to variation in physical composition, namely shape, size and surface/volume ratio. These properties may have influenced the results herein as meats were not standardised prior to cooking, but rather were prepared at the time of carcass dissection, albeit with subcutaneous fat removed. In effect, individual variation of meat properties within dietary regimes may have been a driving factor for this observation.

\section{Sire breed}

The lack of significant difference in moisture content between sire breeds herein is consistent with previous studies [46, 47] reporting between crossbred sheep within raw meats; however, there has been some discrepancy between studies in the water-holding capacity of meats as a function of sheep breed as affected by cooking processes when assessing shear force measurements $[46,48]$. IMF content percentage levels between sires in the raw LTL ranging $3.1-3.9 \%$ within raw meats were comparative to the calculated $4 \%$ mean value reported amongst pure-bred and 1st cross for Australian firstcross prime lambs when examined at around the same age at slaughter, and likewise showing no significant effect on IMF proportions [49].

In the raw state, meats sourced from Dorset sired progeny displayed a greater propensity for $\omega 3$ LC-PUFA deposition than those of other sires types. Australian sheep industry CRC research reported by Ponnampalam, et al. [20] has identified that LC-PUFA content, namely EPA + DHA, increases linearly with the degree of influence of Merino input. Hence, it was anticipated that purebred Merino in the current study would have a tendency for increased $\omega 3$ LC-PUFA deposition compared to the other sire breeds. This was not the case. Such observations are explained by Pannier, et al. [18] and Ponnampalam, et al. [19] stating that differences between sire breeds, whilst significant, are comparatively minor, and are mainly dependent upon site of production, kill date, and individual animal variation, rather than sire breed per se. In the cooked state, differences in $\omega 3$ LC-PUFA concentrations between sires were not statistically evident $(P>0.05)$; a result which may have been influenced by physical characteristic differences between meats.

\section{Gender}

Results between genders within raw meats are consistent with other reports of negligible gender effect on moisture properties [50-52] or IMF [50,53, 54] percentages of lamb meat. In terms of $\omega 3$ LC-PUFA content, the findings herein contrast to those previously reported by
Ponnampalam, et al. [19] reporting that although minor in nature, differences occur between sheep genders under Australian production systems for $\omega 3$ LC- PUFA deposition for the longissimus (on a fresh meat basis), with content in females superior to that of males. However, $\omega 3$ LC-PUFA concentration results within raw meats are in agreement with recent findings by MalauAduli, et al. [32] for these same lamb types at a similar age. Malau-Aduli, et al. [32] attributed these findings to a castration effect of the male lamb genotype which consequently negated any predetermined sex related hormonal differences to those of females.

\section{Interactions}

Comparing with the published literature, the long-chain omega-3 interaction results between sire breed and feeding regime for the uncooked meats align with those of Demirel, et al. [21] who reported results between meat and milk producing sheep breeds under pasture and concentrate management regimes. Previously, De Smet, et al. [55] evaluated that diet plays a greater role on meat fatty acid composition than sheep breed, a finding that is in agreement with our results. From an Australian production viewpoint, the interaction results within raw meats observed herein contrast with those of Ponnampalam, et al. [20] reporting that when slaughtered at the same age, Australian cross bred prime lambs benefit from nutritional intervention to attain comparable $\omega 3$ LC-PUFA content to that contained in meat from purebred Merino.

Throughout the literature, competition in the $\Delta^{6}$-,

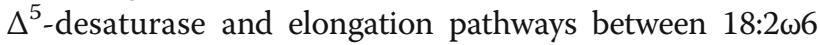
and $18: 3 \omega 3$ for conversion to their respective long-chain

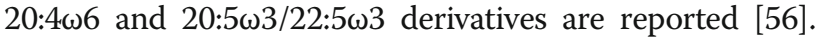
Current findings for conversion through in these pathways dictate that an excess in the conversion of a precursor fatty acid to its long-chain derivatives competes with and thereby limits conversion along the other pathway. From this, the interaction results between breed of sire and diet, showing comparative significance for EPA and EPA + DHA

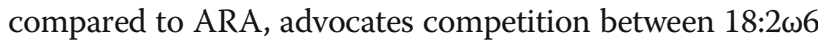
and 18:3 $\omega 3$ desaturase and elongation activities amongst sire breeds based on nutritional regime. Of note is the interaction result of purebred Merino fed the $\mathrm{DCCOH}$ level of supplementation demonstrating an increased ARA content in the raw muscle tissue that may in part, explain the differences in $\omega 3$ LC-PUFA content between sire breeds. As with sire breed by dietary interactions, results between gender and feeding regime within raw meats demonstrate nutritional regulation based on genetic predispositions amongst sheep types, which may again be due to competition between the $\omega 6$ and $\omega 3$ pathways as defined above. 


\section{Nutritional contribution of cooked lamb meat to the human diet}

In a bid to provide information regarding the contribution of lamb meat to supply $\omega 3$ LC-PUFA to the human diet, some reports define minimum EPA + DHA concentrations for raw meats at $24 \mathrm{mg} / 100 \mathrm{~g}$ [18, 57] or $30 \mathrm{mg} / 135 \mathrm{~g}$ [58], corresponding to Australian defined 'source' level $\omega 3$ LC-PUFA at $30 \mathrm{mg} / 100 \mathrm{~g}$ of cooked lamb meat [59]. However, for purposes of defining the nutritional contributions of the experimental meats to consumers, fatty acid results herein were appraised with $100 \mathrm{~g}$ of the cooked lean constituting a single serve portion. Between dietary oil treatments, both the DCCOM (32 mg/100 g EPA + DHA) and DCCOH (38 mg/100 g $\mathrm{EPA}+\mathrm{DHA}$ ) supplementation achieved source level LCPUFA content per single serving of cooked lean meat product, whereas the DCCOC diet $(29 \mathrm{mg} / 100 \mathrm{~g})$ narrowly failed to achieve this status. Between sire breeds, the method of cooking used identified meats from Dorset (36 mg/100 g) and White Suffolk (32 mg/100 g) sired lambs as attaining source level content, whereas purebred Merino (29 mg/100 g) did not. Both ewe (32 mg/100 g) and wether (33 mg/100 g) lambs achieved source level health claimable $\omega 3$ LC-PUFA content for the cooked meats. When the value of docosapentaenoic acid (22:5 $\omega 3$; DPA) was added to all effects, the $\omega 3 \mathrm{LC}$ PUFA (EPA + DHA + DPA) content of the cooked meats contributed $55 \mathrm{mg}$ to the $160-90 \mathrm{mg}$ recommended daily adequate intake for adult men and women, respectively [60]. These findings agree with those of Ponnampalam, et al. [20] indicating that lamb meats have the capacity to contribute substantially to an adequate supply of health beneficial $\omega 3$ LC-PUFA to the diet where fish sources are not available or readily consumed. However, as identified herein, $\omega 3$ LC-PUFA contributions to the diet may depend upon on-farm production inputs. The application of the cooking method employed may likewise be a factor.

In terms of nutritional ratios and indices, all cooked meats, irrespective of effects analysed, demonstrated P/S ratios that were lower than the recommended minimum value of 0.45 ideal for the human diet [61]. The $\omega 6 / \omega 3$ values for all cooked meats were lower than the maximum acceptable value of 4.0 [61]. Atherogenicity (IA) and thrombogenicity (IT) are indices based on assessing atheroma and thrombus formation [37], with the premise that lower values indicate a healthier product in terms of reducing the incidence of coronary heart disease. Within the final cooked product, indices of IA indicated that meats from both DCCOM and $\mathrm{DCCOH}$ supplemented lambs were more beneficial in reducing the risk of atheroma associated with coronary heart disease compared to meats from the DCCO diet. Measurement of IT regardless of the assessed effects were relative to the benchmarked value of 1.33 originally presented by Ulbricht and
Southgate [37] for the lean component of lamb. $\mathrm{h} / \mathrm{H}$ is a nutritional quality index measuring the cholesterol contribution of food types, with higher values indicating a healthier product. In our study $\mathrm{h} / \mathrm{H}$ values ranging from 1.8-2.1 across all effects are in accordance with the nutritional mean of 2.11 for grilled lamb meats as presented by Campo, et al. [62].

\section{Retention of nutrients}

Assessment of retention enables evaluation of the correct loss/degradation or increase of meat nutrients as a direct function of the cooking process [63]. Findings in the current study showing no significant production variable effects on $\omega 3$ LC-PUFA retention indicate that these nutrients generally behaved in the same manner for the cooking mode employed herein - a finding that is supported by our statistical analysis of the data when examining the direct effect of cooking with these dependents (data not presented). Moreover, this finding is corroborated by Alfaia, et al. [63] and Knight, et al. [64] who observed no significant diet by cooking, or breed by cooking interaction effect for fatty acids when examining these parameters for beef and lamb, respectively. The observed significant ARV \% results between genders indicated that the culinary practice employed herein imparted some differences on meat lipid properties; however, when the data was re-assessed as cooking by gender interaction effect (data not presented) there were no differences for these fatty acids. Subsequently, these results indicate that differences of nutrient retention as a function of cooking as indicated in the fatty acid profiles between genders was not sufficient to warrant numerical difference of fatty acid content in meats based on these sheep types.

\section{Conclusions}

The results from this study showed that the inclusion of degummed crude canola oil at $50 \mathrm{~mL} / \mathrm{kg}$ in the sheep finishing ration is capable of providing consumers with a nutritionally beneficial product, particularly with reference to the key $\omega 3$ LC-PUFA. Our results further demonstrated that sire breed plays an important role in regulating $\omega 3$ LC-PUFA deposition in lamb meat for enhancing human nutrition. There was no difference between genders in their capacity to provide these key nutrients. Interaction results demonstrated the significance of feeding regime and genetic predisposition of sheep types on the lamb fatty acid profiles. However, it should be noted that significant differences between production variable effects were only observed for meats in the raw state. The cooking treatment employed did not induce differences in $\omega 3 \mathrm{LC}$ PUFA retention as a function of production effects. Taken together, these results present that combinations of dietary degummed crude canola oil, sheep genetics, and culinary 
preparation method can be used as effective management tools to deliver nutritionally improved $\omega 3$ LC-PUFA lamb meats to consumers. Hence, the overall findings herein support the presented hypotheses for this study.

\section{Abbreviations}

ARV\%: Apparent retention value percentage; DCCOH: Degummed crude canola oil added at a volume of $50 \mathrm{~mL} / \mathrm{kg}$ to the concentrate; DCCO: Degummed crude canola oil; DCCOC: $0 \mathrm{~mL} / \mathrm{kg}$ DM added degummed crude canola oil to the concentrate; DCCOM: $25 \mathrm{~mL} / \mathrm{kg}$ DM of degummed crude canola oil to the concentrate; DHA: Docosahexaenoic acid 22:6w3; DPA: Docosapentaenoic acid 22:5w3); EPA + DHA: Sum of eicosapentaenoic and docosahexaenoic fatty acids; EPA: Eicosapentaenoic acid 20:5 33 ; IMF: Intramuscular fat; PUFA: Polyunsaturated fatty acids; $\omega 3$ LC-PUFA: Long-chain $\left[\geq C_{20}\right.$ ] omega-3 polyunsaturated fatty acids

\section{Acknowledgements}

The authors gratefully acknowledge CopRice Feeds, Cobden, Victoria, Australia for collaborative research support of producing the experimental pellets to specification. We acknowledge with gratitude, the University of Tasmania and the Australian Postgraduate Award of the Commonwealth Government of Australia for awarding a PhD research scholarship to Aaron Ross Flakemore. Acknowledgement goes to Peter Daniel McEvoy who ran the feeding trial component of this study in partial fulfilment of his honours project. Special thanks go to John Otto for undertaking proximate composition and fatty acid analysis of experimental concentrate rations, and for assisting in the cooking process, and to Peter Mansour for assistance with aspects of the fatty acid analyses.

\section{Funding}

We appreciate and acknowledge funding for this project that was provided by the Australian Wool Education Trust (AWET) and the Australian Postgraduate Awards (APA) Scholarship of the Australian Commonwealth Government awarded to the first-named author.

\section{Availability of data and materials}

The datasets used and/or analysed during the current study are available from the corresponding author on reasonable request.

\section{Authors' contributions}

This work was carried out in collaboration between all authors. Author ARF undertook the collection of experimental samples, performed laboratory analyses, interpreted results, and wrote the first draft of the manuscript as part of his PhD. Authors BSM-A, PDN, and AEOM-A contributed in aspects of the experimental work, reading and revision of the draft manuscript. Author AEOM-A as PhD Primary Supervisor, conceived the research idea, wrote the funding grant, experimental design, read and made final changes to the final manuscript as a research article. All authors read and approved the final manuscript.

\section{Ethics approval and consent to participate}

All experimental procedures for this study were conducted with prior approval from the University of Tasmania Animal Ethics Committee (Permit No. A0013839) in accordance with the 1993 Animal Welfare Act and the 2004 Australian Code of Practice for the Care and Use of Animals for Scientific Purposes.

\section{Consent for publication}

Not applicable.

\section{Competing interests}

The authors declare that they have no competing interests that would otherwise interfere with the results pertaining to this research.

\section{Publisher's Note}

Springer Nature remains neutral with regard to jurisdictional claims in published maps and institutional affiliations.

\section{Author details}

${ }^{1}$ Animal Science and Genetics, Tasmanian Institute of Agriculture, School of Land and Food, Faculty of Science, Engineering and Technology, University of Tasmania, Private Bag 54 Sandy Bay, Hobart, TAS 7001, Australia. ${ }^{2}$ College of Medicine and Dentistry, Division of Tropical Health and Medicine, James Cook University, Townsville, QLD 4811, Australia. ${ }^{3}$ Commonwealth Scientific and Industrial Research Organisation, Food, Nutrition and Bi-based Products, Oceans and Atmosphere, G.P.O. Box 1538, Hobart, TAS 7001, Australia.

${ }^{4}$ Animal Genetics and Nutrition, Veterinary Sciences, College of Public Health, Medical and Veterinary Sciences, Division of Tropical Health and Medicine, James Cook University, Townsville, QLD 4811, Australia.

Received: 24 September 2016 Accepted: 19 June 2017 Published online: 21 August 2017

\section{References}

1. Key T, Schatzkin A, Willett WC, Allen NE, Spencer EA, Travis RC. Diet, nutrition and the prevention of cancer. Public Health Nutr. 2004;7:187-200.

2. Kearney J. Food consumption trends and drivers. Philos Trans R Soc B. 2010; 365:2793-807.

3. Biesalski HK. Meat as a component of a healthy diet - are there any risks or benefits if meat is avoided in the diet? Meat Sci. 2005;70:509-24.

4. McAfee AJ, McSorley EM, Cuskelly GJ, Moss BW, Wallace JMW, Bonham MP, et al. Red meat consumption: an overview of the risks and benefits. Meat Sci. 2010;84:1-13.

5. Scollan N, Hocquette JF, Nuernberg K, Dannenberger D, Richardson I, Moloney A. Innovations in beef production systems that enhance the nutritional and health value of beef lipids and their relationship with meat quality. Meat Sci. 2006;74:17-33.

6. McNeill SH. Inclusion of red meat in healthful dietary patterns. Meat Sci. 2014;98:452-60.

7. Micha R, Michas G, Lajous M, Mozaffarian D. Processing of meats and cardiovascular risk: time to focus on preservatives. BMC Med. 2013;11

8. Jacob RH, Pethick DW. Animal factors affecting the meat quality of Australian lamb meat. Meat Sci. 2014;96:1120-3.

9. Mortimer SI, van der Werf JHJ, Jacob RH, Hopkins DL, Pannier L, Pearce KL, et al. Genetic parameters for meat quality traits of Australian lamb meat. Meat Sci. 2014;96:1016-24.

10. Pethick DW, Banks RG, Hales J, Ross IR. Australian prime lamb - a vision for 2020. Int J Sheep Wool Sci. 2006;54:66-73.

11. Hess BW, Moss GE, Rule DC. A decade of developments in the area of fat supplementation research with beef cattle and sheep. J Anim Sci. 2008;86: E188-204.

12. Raes K, De Smet S, Demeyer D. Effect of dietary fatty acids on incorporation of long chain polyunsaturated fatty acids and conjugated linoleic acid in lamb, beef and pork meat: a review. Anim Feed Sci Technol. 2004;113: 199-221.

13. Bessa RJB, Alves SP, Jeronimo E, Alfaia CM, Prates JAM, Santos-Silva J. Effect of lipid supplements on ruminal biohydrogenation intermediates and muscle fatty acids in lambs. Eur J Lipid Sci Technol. 2007;109:868-78.

14. Bhatt RS, Soren NM, Tripathi MK, Karim SA. Effects of different levels of coconut oil supplementation on performance, digestibility, rumen fermentation and carcass traits of Malpura lambs. Anim Feed Sci Technol. 2011;164:29-37.

15. Chilliard Y. Dietary-fat and adipose-tissue metabolism in ruminants, pigs, and rodents - a review. J Dairy Sci. 1993;76:3897-931.

16. Lock AL, Bauman DE. Modifying milk fat composition of dairy cows to enhance fatty acids beneficial to human health. Lipids. 2004;39:1197-206.

17. Wood JD, Enser M, Fisher AV, Nute GR, Sheard PR, Richardson Rl, et al. Fat deposition, fatty acid composition and meat quality: a review. Meat Sci. 2008;78:343-58

18. Pannier L, Ponnampalam EN, Gardner GE, Hopkins DL, Ball AJ, Jacob RH, et al. Prime Australian lamb supplies key nutrients for human health. Anim Prod Sci. 2010;50:1115-22.

19. Ponnampalam EN, Butler KL, Pearce KM, Mortimer SI, Pethick DW, Ball AJ, et al. Sources of variation of health claimable long chain omega-3 fatty Australian lamb slaughtered at similar weights. Meat Sci. 2014;96:1095-103.

20. Ponnampalam EN, Hopkins DL, Butler KL, Dunshea FR, Sinclair AJ, Warner RD. Polyunsaturated fats in meat from Merino, first- and second-cross sheep slaughtered as yearlings. Meat Sci. 2009;83:314-9. 
21. Demirel G, Ozpinar H, Nazli B, Keser O. Fatty acids of lamb meat from two breeds fed different forage: concentrate ratio. Meat Sci. 2006;72:229-35.

22. Otto JR, Malau-Aduli BS, Balogun RO, Nish P, Malau-Aduli AEO. Effect of crude degummed canola oil and ad libitum grazing on plasma metabolites of primiparous Holstein-Friesian cows in a pasture-based system. BMC Vet Res. 2014;10

23. Otto JR, Malau-Aduli BS, Nichols PD, Malau-Aduli AEO. Influence of supplementing pasture-based primiparous Holstein-Friesian dairy cows with crude degummed canola oil on milk fatty acid composition. J Nutr Ther. 2014:3:55-66.

24. Badiani A, Montellato L, Bochicchio D, Anfossi P, Zanardi E, Maranesi M. Selected nutrient contents, fatty acid composition, including conjugated linoleic acid, and retention values in separable lean from lamb rib loins as affected by external fat and cooking method. J Agric Food Chem. 2004;52 5187-94.

25. Badiani A, Nanni N, Gatta PP, Bitossi F, Tolomelli B, Manfredini M. Nutrient content and retention in selected roasted cuts from 3-month-old ram lambs. Food Chem. 1998;61:89-100.

26. Hoke IM, Buege DR, Ellefson W, Maly E. Nutrient and related food composition of exported Australian lamb cuts. J Food Compos Anal. 1999; 12:97-109.

27. Maranesi M, Bochicchio D, Montellato L, Zaghini A, Pagliuca G, Badiani A. Effect of microwave cooking or broiling on selected nutrient contents, fatty acid patterns and true retention values in separable lean from lamb rib-loins, with emphasis on conjugated linoleic acid. Food Chem. 2005;90:207-18.

28. Flakemore A, Balogun R, McEvoy P, Malau-Aduli B, Nichols P, Malau-Aduli A. Genetic variation in intramuscular fat of prime lamb supplemented with varying concentrations of degummed crude canola oil. Int J Nutr Food Sci. 2014;3(3):203-9.

29. Flakemore A, McEvoy P, Balogun R, Malau-Aduli B, Nichols P, MalauAduli A. Degummed crude canola oil supplementation affects fat depot melting points in purebred and first-cross Merino sheep. Animal Vet Sci. 2014;2(3):75-80.

30. Flakemore AR, Malau-Aduli BS, Nichols PD, Malau-Aduli AEO. Omega-3 fatty acids, nutrient retention values, and sensory meat eating quality in cooked and raw Australian lamb. Meat Sci. 2017:123:79-87.

31. ISO. Meat and meat products - determination of moisture content. ISO 1442:1997 International Organization for Standardization, Geneva, Switzerland. 1997

32. Malau-Aduli AEO, Holman BWB, Kashani A, Nichols PD. Sire breed and sex effects on the fatty acid composition and content of heart, kidney, liver, adipose and muscle tissues of purebred and first-cross prime lambs. Anim Prod Sci. 2016:56:2122-32.

33. Bligh EG, Dyer WJ. A rapid method of total lipid extraction and purification. Can J Biochem Physiol. 1959;37:911-7.

34. Anderson BA, Kinsella JA, Watt BK. Comprehensive evaluation of fatty-acids in foods.2.Beef products. J Am Diet Assoc. 1975;67:35-41.

35. Greenfield H, Southgate DTA. Food Composition Data. Production, Management and Use.. 2nd Edition, FAO Rome, 2003 Available to download as PDF at www.fao.org/fileadmin/templates/food_composition/ images/FCD.pdf. Accessed 21 June 2017.

36. Clayton EH. Clayton EH. Graham Centre Monograph No. 4: Long-chain omega-3 polyunsaturated fatty acids in ruminant nutrition: benefits to animals and humans. Eds. T Nugent and C Nicholls, NSW Department of Primary Industries, Wagga Wagga, NSW. 2014. Available at: wwW. grahamcentre.net. Accessed 21 June 2017.

37. Ulbricht TLV, Southgate DAT. Coronary heart-disease - 7 dietary factors. Lancet. 1991;338:985-92.

38. Bessa RJB, Portugal PV, Mendes IA, Santos-Silva J. Effect of lipid supplementation on growth performance, carcass and meat quality and fatty acid composition of intramuscular lipids of lambs fed dehydrated lucerne or concentrate. Livest Prod Sci. 2005;96:185-94.

39. Murphy EW, Criner PE, Gray BC. Comparisons of methods for calculating retentions of nutrients in cooked foods. J Agric Food Chem. 1975;23: 1153-7.

40. SAS. Statistical Analysis Systems Version 9.2, Cary: SAS Institute.

41. Najafi MH, Zeinoaldini S, Ganjkhanlou M, Mohammadi H, Hopkins DL, Ponnampalam EN. Performance, carcass traits, muscle fatty acid composition and meat sensory properties of male Mahabadi goat kids fed palm oil, soybean oil or fish oil. Meat Sci. 2012;92:848-54.
42. de Almeida FA, Sobrinho AGD, Manzi GM, Lima NLL, Endo V, Zeola N. Dietary supplementation with sunflower seeds and vitamin $E$ for fattening lambs improves the fatty acid profile and oxidative stability of the Longissimus lumborum. Anim Prod Sci. 2015;55:1030-6.

43. Lough DS, Solomon MB, Rumsey TS, Elsasser TH, Slyter LL, Kahl S, et al. Effects of dietary canola seed and soy lecithin in high-forage diets on cholesterol content and fatty-acid composition of carcass tissue of growing ram lambs. J Anim Sci. 1992;70:1153-8.

44. Ponnampalam EN, Sinclair AJ, Egan AR, Blakeley SJ, Leury BJ. Effect of diets containing n-3 fatty acids on muscle long-chain n-3 fatty acid content in lambs fed low- and medium-quality roughage diets. J Anim Sci. 2001;79: 698-706.

45. Karami M, Ponnampalam EN, Hopkins DL. The effect of palm oil or canola oil on feedlot performance, plasma and tissue fatty acid profile and meat quality in goats. Meat Sci. 2013;94:165-9.

46. Partida JA, Vázquez E, Rubio MS, Méndez D. Effect of breed of sire on carcass traits and meat quality of Katahdin lambs. J Food Res. 2012;1

47. Santos-Silva J, Mendes IA, Bessa RJB. The effect of genotype, feeding system and slaughter weight on the quality of light lambs - 1. Growth, carcass composition and meat quality. Livest Prod Sci. 2002;76:17-25.

48. Fogarty NM, Hopkins DL, van de Ven R. Lamb production from diverse genotypes. 2. Carcass characteristics. Anim. Sci. 2000;70:147-56.

49. McPhee MJ, Hopkins DL, Pethick DW. Intramuscular fat levels in sheep muscle during growth. Aust J Exp Agric. 2008;48:904-9.

50. Nudda A, Battacone G, Boe R, Manca MG, Rassu SPG, Pulina G. Influence of outdoor and indoor rearing system of suckling lambs on fatty acid profile and lipid oxidation of raw and cooked meat. Ital J Anim Sci. 2013;12

51. Santos VAC, Silva SR, Mena EG, Azevedo JMT. Live weight and sex effects on carcass and meat quality of "Borrego terrincho-PDO" suckling lambs. Meat Sci. 2007;77:654-61.

52. Horcada A, Beriain MJ, Purroy A, Lizaso G, Chasco J. Effect of sex on meat quality of Spanish lamb breeds (Lacha and rasa Aragonesa). Anim Sci. 1998; 67:541-7.

53. Dervishi E, Joy M, Alvarez-Rodriguez J, Serrano M, Calvo JH. The forage type (grazing versus hay pasture) fed to ewes and the lamb sex affect fatty acid profile and lipogenic gene expression in the longissimus muscle of suckling lambs. J Anim Sci. 2012:90:54-66.

54. Okeudo NJ, Moss BW. Intramuscular lipid and fatty acid profile of sheep comprising four sex-types and seven slaughter weights produced following commercial procedure. Meat Sci. 2007;76:195-200.

55. De Smet S, Raes K, Demeyer D. Meat fatty acid composition as affected by fatness and genetic factors: a review. Anim Res. 2004;53:81-98.

56. Calder PC. Polyunsaturated fatty acids, inflammatory processes and inflammatory bowel diseases. Mol Nutr Food Res. 2008;52:885-97.

57. Ponnampalam EN, Butler KL, Jacob RH, Pethick DW, Ball AJ, Edwards JEH, et al. Health beneficial long chain omega-3 fatty acid levels in Australian lamb managed under extensive finishing systems. Meat Sci. 2014;96:1104-10.

58. Williams P. Nutritional composition of red meat. Nutr Diet. 2007;64:S113-S19.

59. FSANZ. Nutrition Information User Guide To Standard 1.2.8 - Nutrition Information Requirements Part B - Nutrition Claims March 2012. 2012.

60. NHMRC. (National Health and Medical Research Council) 'nutrient reference values for Australia and New Zealand including recommended dietary intakes.'. Canberra: Commonwealth Department of Health and Ageing; 2006.

61. Webb EC, O'Neill HA. The animal fat paradox and meat quality. Meat Sci. 2008;80:28-36.

62. Campo MM, Muela E, Olleta UL, Moreno LA, Santaliestra-Pasias AM, Mesana $\mathrm{Ml}$, et al. Influence of cooking method on the nutrient composition of Spanish light lamb. J Food Compos Anal. 2013;31:185-90.

63. Alfaia CMM, Alves SP, Lopes AF, Fernandes MJE, Costa ASH, Fontes C, et al. Effect of cooking methods on fatty acids, conjugated isomers of linoleic acid and nutritional quality of beef intramuscular fat. Meat Sci. 2010;84: 769-77.

64. Knight TW, Knowles SO, Death AF, Cummings TL, Muir PD. Conservation of conjugated linoleic, trans-vaccenic and long chain omega-3 fatty acid content in raw and cooked lamb from two cross-breeds. N Z J Agric Res. 2004:47:129-35. 